\title{
Divisão Sexual do Trabalho e Democracia*
}

\author{
Flávia Biroli
}

Universidade de Brasília (UnB), Brasília, D.F., Brasil. E-mail: flaviabiroli@gmail.com

\begin{abstract}
A s teorias políticas feministas têm contribuído para o avanço das análises teóricas e empíricas sobre a democracia. Trata-se de um conjunto amplo e diverso de abordagens e problemas ao qual se pode atribuir uma base comum, a crítica às formas modernas e contemporâneas da dualidade entre a esfera pública e a esfera privada, tendo como contexto da análise sobretudo as sociedades ocidentais e, entre elas, destacadamente a Europa e a América do Norte. Este artigo analisa o potencial crítico e explicativo dessas teorias, com foco na relação entre divisão sexual do trabalho e democracia, e avalia seu impacto tendo em mente o contexto brasileiro. O ponto de partida da análise é o entendimento de que, ao abordar a divisão sexual do trabalho, o feminismo evidencia as conexões entre as relações de poder no cotidiano e a baixa permeabilidade das democracias contemporâneas.
\end{abstract}

\footnotetext{
* A discussão exposta neste artigo foi desenvolvida no âmbito do projeto de pesquisa "Divisão sexual do trabalho e os limites da democracia: elaborações teóricas a partir das desigualdades de gênero no Brasil contemporâneo" (PQ, Conselho Nacional de Desenvolvimento Científico e Tecnológico - CNPq). Ela se beneficia do diálogo com pesquisadoras e estudantes do Grupo de Pesquisa sobre Democracia e Desigualdades - Demodê (www.demode.unb.br). Sou grata às participantes da AT "Democracia e desigualdades" do $39^{\circ}$ Encontro Anual da Associação Nacional de Pós-Graduação e Pesquisa em Ciências Sociais (Anpocs), com quem tive a oportunidade de discutir uma versão preliminar deste texto, em especial Céli Pinto, Luciana Ballestrin e Luis Felipe Miguel. Agradeço também os comentários dos pareceristas anônimos de DADOS - Revista de Ciências Sociais, que sem dúvida contribuíram para a versão aqui apresentada.
}

DADOS - Revista de Ciências Sociais, Rio de Janeiro, vol. 59, no3, 2016, pp. 719 a 681. 
Com todas as transformações que ocorreram nas últimas décadas, as mulheres continuam a dedicar mais tempo às tarefas domésticas e a ter rendimentos médios menores do que os homens pelo trabalho desempenhado fora de casa. Isso se dá mesmo quando, como acontece no Brasil de hoje, acompanhando tendências verificadas em outras partes do mundo, as mulheres têm mais tempo de ensino formal que os homens e são a maior parte dos indivíduos que completam o ensino superior. A ampliação do acesso à educação e as transformações no padrão ocupacional não permitiram superar as desigualdades entre mulheres e homens nos rendimentos e a maior precariedade das primeiras nas relações de trabalho (A. Araújo e Lombardi, 2013; Bruschini, 2006; Bruschini e Lombardi, 2001; 2002).

As relações de trabalho também expõem com clareza os padrões hierárquicos nas relações entre as mulheres, organizados por outras variáveis, entre as quais se destacam classe e raça. Como afirmou Heleieth Saffioti (2013:133), "se as mulheres da classe dominante nunca puderam dominar os homens de sua classe, puderam, por outro lado, dispor concreta e livremente da força de trabalho de homens e mulheres da classe dominada", o que tem expressão clara no recurso das mulheres mais ricas ao trabalho doméstico mal remunerado e precarizado das mais pobres. Nesse caso, a concentração de renda é um componente incontornável das hierarquias, embora não suspenda os padrões de gênero na responsabilização pelo trabalho doméstico e no acesso a ocupações. O ponto aqui é que as desvantagens que atingem as mulheres não são suficientes para que se faça delas um grupo minimamente homogêneo. Nessa dinâmica, gênero, raça e classe organizam conjuntamente sua vivência. Em outras palavras, o gênero não se configura de maneira independente em relação à raça e à classe social, nem é acessório relativamente a essas variáveis.

Gostaria de deixar anotado que, mesmo tendo em mente as formas múltiplas e cruzadas de opressão e de construção das identidades, mantenho a referência a mulheres e homens ao falar em gênero porque as práticas às quais me refiro atendem em grande medida a um modo binário de organização que ao mesmo tempo constrange e produz comportamentos. Vale esclarecer, ainda, que embora a parcela majoritária da discussão sobre a produção do gênero esteja situada no âmbito da sexualidade, entendo que a construção binária das categorias feminino e masculino ocorre também por meio de prescrições e julgamentos que responsabilizam e conformam habilidades e preferências, com forte expressão no âmbito da divisão das responsabilidades e do traba- 
lho. Como parte desse processo, são ativados filtros que incidem sobre as mulheres no acesso a ocupações e no acesso ao âmbito da política institucional, constituindo padrões sistemáticos de exclusão e de marginalização. Elas constituem, assim, um grupo onerado pelo cotidiano de trabalho não remunerado, direcionado a ocupações específicas, relativamente menos remunerado no trabalho e sub-representado na política.

A literatura sobre divisão sexual do trabalho que será discutida neste artigo permite que sejam apresentados dois axiomas. Em conjunto com subsídios empíricos mobilizados para testá-los e situá-los no contexto brasileiro, eles organizam a discussão e servem como ponto de partida para a hipótese apresentada subsequentemente:

Axioma 1 - A divisão sexual do trabalho é uma base fundamental sobre a qual se assentam hierarquias de gênero nas sociedades contemporâneas, ativando restrições e desvantagens que produzem uma posição desigual para as mulheres.

Axioma 2 - Essas hierarquias de gênero assumem formas diferenciadas segundo a posição de classe e raça das mulheres. A divisão sexual do trabalho não encontra, no entanto, um limite nas vantagens de classe e de raça - impacta as mulheres por serem mulheres, ainda que isso não signifique padrões resultantes comuns.

É a partir deles que foi possível formular a hipótese que consiste no eixo central deste artigo:

Hipótese - A divisão sexual do trabalho doméstico implica menor acesso das mulheres a tempo livre e a renda, o que tem impacto nas suas possibilidades de participação política e nos padrões que essa participação assume.

Estudos feitos no Brasil, acompanhando a literatura internacional sobre participação política, têm mostrado que práticas e valores que sustentam uma divisão sexual do trabalho fundada em concepções convencionais do feminino e do masculino têm impacto no acesso das mulheres a cargos políticos (C. Araújo e Scalon, 2006; C. Araújo e Alves, 2007; Miguel e Biroli, 2011) e que "a ausência da mulher na esfera política não pode ser posta unicamente na conta dos limites da democracia liberal", com o funcionamento seletivo de suas instituições e suas "limitações estruturais para incluir novos sujeitos" (Pinto, 2010:22). É nesse ponto que se estabelecem as conexões entre os axiomas e a hipótese central de trabalho deste artigo. 
O sentido dessa hipótese é que, embora as hierarquias de classe e raça incidam na definição de quem tem acesso aos espaços de poder, a divisão sexual do trabalho e as formas da construção do feminino a ela relacionadas fazem com que as mulheres, por serem mulheres, tenham menores chances de ocupar posições na política institucional e de dar expressão política, no debate público, a perspectivas, necessidades e interesses relacionados a sua posição social. Têm, com isso, menores chances também de influenciar as decisões e a produção das normas que as afetam diretamente. A cidadania das mulheres é, portanto, comprometida pela divisão sexual do trabalho, que em suas formas correntes converge em obstáculos ao acesso a ocupações e recursos, à participação política autônoma e, numa frente menos discutida neste estudo, à autonomia decisória na vida doméstica e íntima ${ }^{1}$.

O artigo está organizado em três seções, além desta introdução. A primeira discute o primeiro axioma, recuperando abordagens que colocam a divisão do trabalho no centro da dinâmica de opressão das mulheres e, como será discutido, da produção do gênero. São abordagens que entendem que essa relação é fundamental para a compreensão não apenas da posição desigual das mulheres, mas da organização das relações de poder nas sociedades contemporâneas de forma mais ampla. Na segunda seção, exploro o segundo axioma, discutindo a produção do gênero nas relações de trabalho como algo que se dá na interseção com classe (em uma concepção que, assumo desde já, desliza entre classe e renda) e raça. Por fim, procuro avançar na discussão da hipótese central deste artigo, que conecta a divisão sexual do trabalho à sub-representação política das mulheres, a partir do instrumental teórico e empírico mobilizado nas seções anteriores. Com isso, caminho para uma breve conclusão, centrada no impacto do conjunto dos problemas abordados para a análise da democracia, tendo como foco a posição desigual das mulheres. Pretendo, assim, contribuir para a incorporação dessa dimensão fundamental das relações de gênero, que é a divisão sexual do trabalho, aos modelos teóricos que orientam os estudos sobre a democracia.

\section{DIVISÃO SEXUAL DO TRABALHO E A POSIÇÃO DESIGUAL DAS MULHERES}

A divisão sexual do trabalho não é um tema novo ou que tenha sido pouco discutido nas últimas décadas. O estudo das formas assumidas pelo trabalho feminino foi definido como "a porta de entrada dos estu- 
dos sobre a mulher na academia brasileira", "tendo sido o primeiro [tema] a logo conquistar o selo da legitimidade" nas universidades do país (Bruschini, 1994, apud Neves, 2013:405). É o problema central da obra que pode ser considerada pioneira das pesquisas contemporâneas sobre a posição das mulheres na sociedade brasileira, A Mulher na Sociedade de Classes, de Heleieth Saffioti, publicada pela primeira vez em 1969.

As pesquisas sobre gênero e trabalho compartilham o entendimento de que a divisão sexual do trabalho atravessa as relações sociais e é fundamental na sua organização. Sua problematização permite questionar "categorias e métodos que aprendemos a considerar neutros", como constatou, ainda nos anos 1980, Elizabeth Souza-Lobo (1991:149). Isso não significa, no entanto, que tenha sido incorporada como problema - seja nos estudos sobre trabalho, que podem padecer, ainda citando Souza-Lobo, de categorias "sexualmente cegas", seja nos estudos sobre gênero, nos quais a conexão com a divisão sexual do trabalho nem sempre avança para além de sua menção como enquadramento teórico adotado de partida.

Isso remete, sem dúvida, a uma dinâmica mais ampla de resistências de diversos tipos, no campo das Ciências Sociais, que fixam "fronteiras entre teorias gerais e particulares", compartimentando "problemáticas que atravessam as relações sociais e [que], ao serem circunscritas a espaços 'específicos', são isoladas e perdem todo alcance e extensão" (Souza-Lobo, 1991:149). Essa dinâmica é, ao mesmo tempo, característica dos processos de especialização e do isolamento de problemas, experiências e atores em nichos que não são incorporados às teorias e explicações de caráter mais geral. Esses nichos se definem internamente às disciplinas, mas também atuam na produção das fronteiras disciplinares, seletivas na sua permeabilidade a temas e problemas. Assim, se na Sociologia a divisão sexual do trabalho ganhou terreno, mas permanece ainda como questão específica, na Ciência Política não alcança esse estatuto ${ }^{2}$.

Hirata e Kergoat (2007), em um balanço feito décadas mais tarde e mais focado na produção francesa, chamam a atenção para outro limite: a noção de "divisão sexual do trabalho" se tornaria mais comum nas Ciências Humanas, mas de uma forma que reduz sua radicalidade, apresentando descrições desprovidas de conotação conceitual. No mesmo texto, elas constatam a menor atenção ao trabalho doméstico a 
partir dos anos 1990. Ele passaria a figurar de maneira fraca "em termos como 'dupla jornada', 'acúmulo' e 'conciliação de tarefas', como se fosse apenas um apêndice do trabalho assalariado" (idem:599).

Joan Williams (2010:112-113), agora com mais atenção à agenda das pesquisas nos Estados Unidos, afirma que o par trabalho-família foi o tema predominante nos anos 1980, mas teria sido suplantado, nas décadas seguintes, pelos estudos sobre os pares sexo-violência, nos anos 1990, e identidade-sexualidade, nos anos 2000. Não há correspondência no caso brasileiro. Sexualidade e violência foram, sem dúvida, temáticas que tiveram atenção crescente também no Brasil, mas sem que a perda de espaço dos estudos sobre gênero e trabalho tenha se dado em igual medida. Uma explicação pode ser o fato de que foi a partir dos anos 1970 que a presença das mulheres no mercado de trabalho no país se ampliou progressiva e significativamente: em 1970, 18\% das mulheres exerciam trabalho remunerado (Fundação Carlos Chagas, s/d), em 2012, a taxa de ocupação de mulheres de 16 a 59 anos chegaria a 64,2\% (Raseam, 2015). Mesmo sendo bastante inferior, ainda, à taxa de ocupação dos homens no mesmo ano, que foi de $86,2 \%$, essa maior ocupação entre as mulheres representa mudanças importantes nas relações de trabalho como um todo e nas relações de gênero especificamente.

Essa parece ser uma das razões para a atenção despendida, no ambiente acadêmico brasileiro, às conexões entre gênero e trabalho nas décadas de 1990 e 2000 . As principais revistas feministas brasileiras tiveram dossiês sobre gênero e trabalho nos anos 2000, e a produção sobre o tema tem sido contínua ${ }^{3}$. Mas enquanto uma busca feita com as palavras-chave "trabalho doméstico" e "trabalho doméstico remunerado" nas edições disponíveis na plataforma SciElo das revistas Estudos Feministas e Pagu retornou 27 e 24 artigos, respectivamente, a busca feita nas mesmas revistas com a combinação das palavras "trabalho e democracia" ou "trabalho e política" teve como retorno "zero" artigo ${ }^{4}$. É apenas um indício, que precisaria ser explorado em pesquisa voltada especificamente para a produção acadêmica, mas a hipótese que aqui levanto para sua explicação remete às fronteiras disciplinares: a maior parte dos estudos sobre a divisão sexual do trabalho está concentrada na área de Sociologia, como dito, enquanto o tema é praticamente ausente da área de Ciência Política. O problema é que, segundo sustento neste artigo, essa divisão tem impacto profundo nas democracias contemporâneas, uma vez que o equilíbrio entre trabalho remunerado e não remunerado e o acesso diferenciado a ocupações incidem nas 
hierarquias que definem as possibilidades de presença e de exercício de influência no sistema político.

No debate teórico que referenciou as análises sobre gênero e trabalho nas últimas décadas, foi entre as abordagens feministas marxistas que essa aproximação ganhou maior atenção. A posição das mulheres nas relações de trabalho está no cerne das formas de exploração que caracterizam, nelas, a dominação de gênero (ou o patriarcado). Trata-se de um conjunto variado de abordagens, atravessado pelo problema da correlação entre a divisão do trabalho doméstico não remunerado, a divisão do trabalho remunerado e as relações de poder nas sociedades contemporâneas.

Nos textos publicados a partir dos anos 1970 e reunidos nos dois volumes de L'Ennemi Principal, Christine Delphy (2013a; 2013b) definiu capitalismo e patriarcado como sistemas distintos que se sobrepõem e incidem um sobre o outro, assumindo uma posição que a tornaria uma das representantes destacadas das teorias feministas dos sistemas duais. De modo semelhante - e suspendendo aqui diferenças entre as autoras que são pouco significativas para meus argumentos neste texto -, Michèle Barrett (1988) afirmaria que a divisão sexual do trabalho não pode ser atribuída a qualquer necessidade histórica do capitalismo. Uma explicação que não leve isso em conta produziria uma fusão equivocada entre uma tendência geral - a separação entre casa e ambiente de trabalho - e sua forma histórica particular.

Essa forma histórica particular, na qual a separação entre casa e trabalho foi fundamental, teria, segundo a autora, resolvido um problema incontornável, expresso na pergunta "quem tomaria conta das crianças?" (e, podemos complementar, dos doentes, dos deficientes e dos idosos), recorrendo a "uma ideologia de gênero que precede o capitalismo, em benefício dos homens" (Barrett, 1988:164-165) 5, 6. Pode-se, ainda dentro da perspectiva assumida por Barrett, considerar que a separação entre casa e trabalho produziu uma situação que seria justificada, então, pela ideologia de gênero na modernidade.

O fato de a industrialização ter transferido parte da produção realizada no espaço doméstico para as fábricas não restringiu a casa a um espaço reprodutivo. A responsabilização desigual de mulheres e homens por um trabalho que nessas abordagens é definido como produtivo e não remunerado seria a base do sistema patriarcal no capitalismo. O patriarcado, como sistema político, consistiria numa estrutura de exploração 
do trabalho das mulheres pelos homens. No centro da análise, portanto, está a divisão sexual do trabalho e o fato de que tenha impacto muito distinto nos dois grupos (ou classes) que são, assim, produzidos: as mulheres, que têm sua força de trabalho apropriada, e os homens, que se beneficiam coletivamente desse sistema (Delphy e Leonard, 2004).

A distinção entre trabalho remunerado e não remunerado é colocada, assim, no cerne das formas de exploração características do sistema patriarcal no mundo capitalista. O trabalho que as mulheres fornecem gratuitamente, como aquele que está envolvido na criação dos filhos e no cotidiano das atividades domésticas, libera os homens para que se engajem no trabalho remunerado. São elas apenas que fornecem esse tipo de trabalho gratuitamente, e sua gratuidade se define numa relação, o casamento. É nele que o trabalho gratuito das mulheres pode ser caracterizado como não produtivo. Os produtos que não têm valor quando decorrem do trabalho da mulher em casa passam, no entanto, a ter valor econômico fora da casa, quando atendem às necessidades de outras pessoas que não o marido (Delphy, 2013a:123). Vale observar que isso inclui, para Delphy, a produção dos alimentos, as roupas lavadas, mas também o cuidado com as crianças e as formas de apoio moral e trabalho sexual e reprodutivo que têm sido parte do casamento. Daí a afirmação de que "se um homem se casa com sua empregada doméstica ou com uma prostituta, o mesmo trabalho e a mesma mulher repentinamente se tornam não remunerados e 'improdutivos'" (Delphy e Leonard, 2004:84).

Os efeitos dessa forma de exploração não permanecem, no entanto, nos limites da casa. As "obrigações familiares" restringem e moldam as ocupações fora de casa, ao mesmo tempo que se tornam um pretexto para ampliar a exploração capitalista do trabalho remunerado das mulheres (Delphy, 2013a:51).

Essa exploração se daria em dois níveis, um coletivo e um individual. O primeiro consistiria em "atribuir coletivamente a responsabilidade pelas crianças às mulheres, e liberar coletivamente os homens" dessa mesma responsabilidade (ibidem: 131). É sobre a apropriação coletiva do trabalho das mulheres que se organizaria a exploração individual, isto é, a apropriação do trabalho de uma mulher por seu marido. É justamente porque sua liberação é coletiva e institucionalizada que um homem poderia "exigir como retorno pela sua participação na provi- 
são financeira das crianças a totalidade da força de trabalho de sua mulher" (idem:133). Essa exploração não termina no casamento. Com o divórcio, as mulheres permanecem responsáveis pelas crianças e vivenciam desdobramentos da apropriação do seu trabalho - por um lado, os limites na sua formação e profissionalização que derivam das responsabilidades assumidas durante o casamento; por outro, os limites que se impõem pelo fato de que permanecem as principais responsáveis pelas crianças terminado o casamento. Assim, se as mulheres casadas são as que sofrem diretamente a "opressão comum" fundada na divisão do trabalho, as restrições sofridas pelas mulheres divorciadas e pelas mulheres solteiras com filhos expõem o caráter sistêmico e institucionalizado da opressão: elas vivenciam os custos ampliados da ruptura com os padrões de dependência vigentes, sendo essa ruptura voluntária ou não. Em suma, é justamente o caráter institucional da exploração no casamento que torna a situação das mulheres fora dele potencialmente tão ruim que o casamento aparece como um mal menorcomo "a melhor carreira, economicamente falando" (idem:126) ${ }^{7}$.

Trata-se, assim, de uma dinâmica que define padrões conjugais, afetivos, ocupacionais e incide na construção dos direitos. A divisão sexual do trabalho doméstico, em seu entrelaçamento com a organização do trabalho assalariado no capitalismo, explicaria, por exemplo, o fato de que a jornada de trabalho "normal" seja aquela de um indivíduo liberado do trabalho cotidiano necessário para sua própria manutenção (Delphy, 2013a). Se consideramos o fato de que estão em questão o acesso a tempo livre e a renda, ponto central para a discussão que aqui proponho, temos uma base para o entendimento de que as possibilidades de participação no sistema político não variam apenas segundo a posição socioeconômica relativa da unidade familiar (medida, por exemplo, pela renda média familiar e pelo tipo de ocupação à qual o chefe de família tem acesso), mas guardam correspondência com as hierarquias de gênero.

A produção francesa que se define e se orienta pelo conceito de "relações sociais de sexo" também abordou, a partir dos anos 1980, a relação entre o mundo do trabalho remunerado, o do trabalho doméstico e a configuração das hierarquias de gênero (Kergoat, 1982 e 2010). Danièle Kergoat e Helena Hirata (2007), em um balanço dessa produção, constatam a "plasticidade" dessas relações, destacando que se em algumas sociedades, como a francesa, a "condição feminina" sem dúvida melhorou, a distância entre mulheres e homens continuava significativa. 
Tempo livre e renda são eixos fundamentais dessa distância. Ao mesmo tempo, no século XXI cresceria significativamente o número de mulheres que ocupam cargos de poder e com alta remuneração em empresas e corporações - "pela primeira vez na história do capitalismo" teríamos "uma camada de mulheres cujos interesses diretos" se opõem frontalmente aos das assalariadas e que desempenham trabalho em tempo parcial precarizado (Hirata e Kergoat, 2007:601).

Em diálogo mais direto com a produção em língua inglesa, Sylvia Walby (1990), que define sua própria posição como um alargamento de análises sistêmicas anteriores, também focou nas mudanças históricas. Embora mantenha a relevância das relações na esfera doméstica-familiar, o olhar aqui se desloca para as relações de trabalho fora da casa no mundo contemporâneo ${ }^{8}$.

Na sua forma prévia à intensificação do processo de industrialização e seu olhar é para como se deu esse processo na Europa Ocidental, em especial na Grã-Bretanha -, o patriarcado teria se caracterizado pela exclusão das mulheres e pelo controle direto de um homem sobre uma mulher, exercido da sua posição de marido ou de pai. A família estava no centro dessa dinâmica de opressão, por ela denominada "patriarcado privado". Mudanças históricas diretamente relacionadas às formas assumidas pelo capitalismo em sua fase industrial teriam atuado para que essas relações se modificassem. A visão de Walby é de que a opressão das mulheres permaneceu, porém transformada. "Elas não são mais barradas das arenas públicas, mas são ainda assim subordinadas nessas arenas", a expropriação do seu trabalho se daria agora de forma mais coletiva do que individual, e a casa, que continuaria a ser um espaço de opressão, não seria mais o principal lugar em que transcorrem as vidas das mulheres (Walby, 1990:178).

No que seria então chamado de "patriarcado público" pela autora, Estado e mercado de trabalho passariam a ser as dimensões em que os constrangimentos se organizam e se institucionalizam. Novas formas de inclusão seriam então acompanhadas de formas também renovadas de opressão e de controle.

$\mathrm{O}$ vínculo entre trabalho remunerado e trabalho doméstico não remunerado no âmbito familiar permaneceria significativo, mas, além de estar longe de ser exclusivo na construção das hierarquias entre mulheres e homens, não poderia ser colocado como a origem da cadeia causal que as posiciona desigualmente nas sociedades ocidentais con- 
temporâneas: a opressão e as desigualdades de gênero, analisadas em um nível estrutural, se organizariam numa dinâmica que vai do mercado para a família (Walby, 1990:57).

A família, por sua vez, assumiria formas cada vez mais diversificadas. Sem aderir a uma visão unidimensional das causalidades, a autora vê nas transformações internas ao capitalismo incentivos e pressões que tiveram efeito na reorganização da vida doméstica, em especial na domesticidade das mulheres. Para ela, a demanda por força de trabalho em diferentes momentos nos séculos XIX e XX esteve em conflito com a estratégia do patriarcado de manter as mulheres em casa e privatizar seu trabalho. Vale lembrar, no entanto, que foi essa privatização que tornou mais barata a mão de obra feminina, comparativamente à masculina. Ela explicaria as dificuldades na luta por direitos trabalhistas pelas mulheres, como o direito à equiparação salarial. A permanência da atribuição desigual das responsabilidades pela vida doméstica, sobretudo pela criação dos filhos, seria ainda um fator que, como dito anteriormente, tornaria a exploração da mão de obra feminina mais aguda, pelo fato de desdobrar-se em trajetórias profissionais descontinuadas e em maiores conflitos entre as exigências domésticas e o cotidiano de trabalho fora de casa.

As mudanças políticas que foram conquistadas pela chamada primeira onda do feminismo, como o direito ao voto e à propriedade, o acesso à educação e, mais lentamente, o direito a deixar um casamento, criaram um contexto favorável para o acesso ao trabalho remunerado, $\mathrm{o}$ que por sua vez aumentou potencialmente a independência das mulheres - para, por exemplo, deixar de fato um casamento, já que o direito ao divórcio pode significar pouco quando as alternativas para o próprio sustento e o dos filhos são restritas. O comportamento sexual também se modificaria, segundo ela, em decorrência dessas novas condições materiais. A vitória da primeira onda do feminismo se deu sobretudo "no nível político do Estado", enquanto "as mudanças eventuais no nível econômico criaram a possibilidade material de que as mulheres tirassem vantagem da sua independência legal" (Walby, 1990:185), o que permitiria uma interpretação de que as mudanças na posição das mulheres são o resultado combinado das forças capitalistas e das lutas feministas (idem:59).

Ainda que as mulheres tenham entrado em desvantagem na esfera pública (Walby, 1990:180) e permaneçam ainda em desvantagem no 
acesso a renda e a ocupações socialmente valorizadas, essa análise pode colaborar para compreender que:

1) não é necessário reduzir a importância do acesso a direitos formais para expor o fato de que são vividos em condições desiguais por mulheres e homens;

2) os âmbitos político e econômico produziram conjuntamente as condições de possibilidade (e as restrições) nas quais as mulheres fizeram suas escolhas e os grupos feministas organizados atuaram;

3) o acesso desigual das mulheres ao trabalho remunerado remete a questões "de poder material assim como de valores normativos" (Walby, 1990:57).

Em conjunto, as abordagens discutidas nesta seção destacam os constrangimentos materiais que constituem as escolhas feitas pelas mulheres, deixando claro que não são suas "escolhas" que geram esses constrangimentos, mas sim o contrário. As motivações podem não se apresentar para os próprios indivíduos como desdobramentos das estruturas que assim as configuraram (ibidem:58). Justamente por isso, motivações e escolhas deveriam ser situadas na dinâmica social em que são produzidas, e não explicadas numa dimensão individual e a partir de uma perspectiva voluntarista (Biroli, 2013; Delphy e Leonard, 2004; Pateman, 1985).

Há, nessas análises, um reconhecimento de que o capital e as formas correntes de exploração do trabalho incidem sobre a vida doméstica, a conjugalidade, a divisão cotidiana das tarefas. Essa divisão, por sua vez, atua na forma de constrangimentos e incentivos à atuação em outras esferas da vida, entre elas a do trabalho e a da política institucional. Por outro lado, a solução não estaria em uma análise meramente econômica, mas de economia política (Walby, 1990:56).

A produção do gênero na divisão sexual do trabalho se estabeleceria, assim, material e ideologicamente. É nessas duas dimensões, conectadas, que as alternativas, os incentivos, os constrangimentos e os riscos se definem.

Hoje, há mais do que a dependência das mulheres em relação a homens específicos alimentando esses circuitos. A "ideologia da dependência emocional, física e 'moral'" (Barrett, 1988:179) pode não ter desaparecido, mas certamente modificou-se com a ampliação do acesso das mulheres ao trabalho remunerado e à educação formal. A atuação dos 
movimentos feministas para a redefinição dos direitos e ressignificação das relações de gênero teve impacto na construção das identidades, nas possibilidades que se definem cotidianamente. As diferenças entre a ideologia familista e a organização de fato da família, que sempre foram relevantes, se ampliaram (Barrett, 1988:204-205). Apenas parte das mulheres, e também dos homens, esteve e está hoje em posição que permite tomar parte dessas relações no modelo provedor/dona de casa. Os arranjos familiares são cada vez mais plurais e diversos, o número de mulheres na posição de chefe de família aumentou significativamente.

É possível sustentar, no entanto, que a família permanece, ainda assim, como nexo na produção do gênero e da opressão às mulheres. Mas a noção de dependência, em especial quando ela pretende expor a relação entre mulheres e homens com quem são ligadas pelo casamento ou por filiação, parece ser hoje menos adequada. Opto, assim, pela noção de vulnerabilidade, que entendo que corresponde mais adequadamente à posição desigual das mulheres atualmente ${ }^{9}$.

O problema principal explorado nesta seção é a conexão entre a vulnerabilidade relativa das mulheres e a divisão sexual do trabalho, que constrange estruturalmente suas possibilidades. Desse constrangimento não decorre, no entanto, uma mesma posição para todas as mulheres.

\section{POSIÇÕES DIFERENCIADAS: CONVERGÊNCIAS ENTRE GÊNERO, RAÇA E CLASSE}

Na seção anterior, argumentei no sentido de que a divisão sexual do trabalho produz o gênero. A literatura mobilizada destaca a divisão sexual do trabalho como base para a opressão das mulheres: o gênero é assim produzido na forma da exploração do seu trabalho e da vulnerabilidade relativa que as atinge. Para ser mais precisa, diferenças que definiriam o feminino e o masculino de maneira dual, embora sejam codificadas como algo que corresponderia ao sexo biológico, decorrem da atribuição distinta de habilidades, tarefas e alternativas na construção das suas vidas para mulheres e homens. Essas diferenças, que presumem normas masculinas, são mobilizadas para justificar as desvantagens econômicas das mulheres (Williams, 2010:128). Não estou afirmando que a divisão sexual do trabalho produz o gênero isoladamente, mas que tem um papel fundamental na sua construção. 
Em algumas das abordagens mobilizadas, o foco na divisão sexual do trabalho tem como desdobramento a definição das mulheres como grupo - ou classe - que ganha unidade em contraposição aos homens, melhor dizendo, às vantagens deles na atribuição diferenciada das responsabilidades, nessa forma binária de construção do gênero. A divisão sexual do trabalho permitiria ressaltar uma forma de opressão que seria comum às mulheres (Delphy, 2013a:50).

Há, de fato, um tipo de exploração que se efetiva porque o trabalho doméstico é realizado pelas mulheres - mas isso não significa que seja realizado nas mesmas condições por mulheres brancas e negras, pelas mais ricas e pelas mais pobres. Ao mesmo tempo, o acesso ao mercado de trabalho também se dá de forma distinta, segundo raça e posição de classe das mulheres. Se levamos em consideração esses dois fatos conjuntamente, a conexão entre divisão sexual do trabalho não remunerado e do trabalho remunerado organiza as vidas das mulheres, mas o faz de maneiras distintas e as afeta de forma e em graus desiguais.

Entendo, assim, que a divisão sexual do trabalho produz o gênero, de fato, mas essa produção se dá na convergência entre gênero, classe e raça ${ }^{10}$. Em outras palavras, o gênero não é produzido isoladamente em relação a outras variáveis que, em um dado contexto, são relevantes no posicionamento e identificação das pessoas. Como afirma Elizabeth Spelman (1988:162), as mulheres vivem em um mundo no qual não há apenas sexismo, mas racismo, classismo e outras formas de opressão, em um mundo, portanto, em que "o 'problema da diferença' é na realidade o problema do privilégio".

Se concordarmos - e é esta minha posição - que as diferenças se definem na forma de privilégios e desvantagens, não estamos tratando de uma questão identitária, mas de posições que ganham sentido em hierarquias. Um exemplo: na construção do feminino e do masculino no cuidado diferenciado com as crianças, não é a gestação ou a atenção amorosa que coloca a mulher na posição de se responsabilizar prioritariamente pelas crianças, mas a atribuição das responsabilidades em relações hierárquicas. $\mathrm{O}$ fato de que não seja apresentada como resultante da permanência da "chefia" masculina, mas como a efetivação de tendências naturais, não significa que as relações de autoridade não existam, mas que não se definem na forma do exercício aberto do controle sobre as atividades e o tempo das mulheres ${ }^{11}$. 
O fato de serem mulheres "pode antecipar algo sobre os constrangimentos e expectativas" que se apresentam a elas (Young, 1997:32), mas é justamente porque as mulheres não estão sempre em desvantagem que a generalização da posição de algumas mulheres foi denunciada como uma forma de tornar invisíveis as experiências de outras mulheres e as relações de poder que as diferenciam. Volto ao exemplo dado há pouco, da maternidade. As expectativas e julgamentos que conferem sentido à maternidade não são igualmente mobilizadas ou incidem da mesma forma sobre diferentes grupos de mulheres. Mesmo que essas expectativas, que tomaram forma inicialmente no ambiente da burguesia europeia no século XIX, atravessem diferentes classes sociais e sejam ativadas em contextos culturais distintos - e há boas razões para entendermos que isso se dê (Badinter, 1985; Biroli, 2014a; Delphy, 2013a e 2013b) -, os constrangimentos, materiais e ideológicos que se impõem às mulheres variam e são vivenciados distintamente de acordo com a classe social, a raça e, nesse caso, de maneira muito central, também a sexualidade.

A denúncia da maternidade como dispositivo de poder, feita pelo feminismo, assim como a agenda da luta pelo aborto, nem sempre são capazes de incluir o fato de que, para a população negra, em diferentes países do Ocidente, o controle da capacidade reprodutiva das mulheres e a vivência da maternidade têm se dado de formas específicas, que não correspondem às formas de controle e a essa vivência entre as mulheres brancas. Quando se leva em consideração raça e classe, ganha importância ressaltar que a imposição da maternidade está tão distante do respeito à autonomia das mulheres como cidadãs quanto as políticas que lhes recusam a maternidade ${ }^{12}$. Para muitas mulheres, e sobretudo em condições de precariedade e violência, a maternidade pode motivar a construção de identidades políticas e a ação em favor dos seus direitos - entre eles o de ter condições adequadas para criar seus filhos. Entre as feministas negras, a mobilização da maternidade como símbolo de poder vem sendo compreendida como reação à violência e ao racismo que oprime seus filhos, e não como uma forma de ação política de menor valor ou maturidade (Collins, 2009:209). Não se trata, entendo, de uma nova forma de idealização, mas do reconhecimento de que o "matriarcado da miséria" (Carneiro, 2011:127) produz identidades e ações políticas.

Do mesmo modo, a divisão sexual do trabalho não se organizou historicamente em um único padrão. Esse padrão varia quando se conside- 
ra a posição de diferentes mulheres (e homens), levando em conta as relações de classe e de raça. Se os homens foram e permanecem sendo os beneficiários da exploração do trabalho doméstico realizado pelas mulheres, eles também não formam, é claro, um grupo homogêneo. Assim como a posição das mulheres na divisão sexual do trabalho é desigual, os homens "não se beneficiam igualmente do sexismo" (Hooks, 1984:69) e das vantagens que assume nessa divisão. A "exploração comum a todas" (Delphy, 2013a:52) não é vivida da mesma maneira, assim como o benefício que os homens encontram não coloca a todos no mesmo patamar nas hierarquias que organizam o mundo do trabalho. Uma questão importante na divisão do trabalho, o contraponto entre "salário familiar" ganho pelos homens e a domesticidade das mulheres, reflete uma experiência bastante particular (cf. a crítica de Hooks, 1984, a Betty Friedan, 2001) - daí o entendimento de que a defesa do "salário familiar" pelos trabalhadores organizados tenha sido uma estratégia equivocada e que promove divisões na classe trabalhadora, resultando em benefícios não para os homens, mas para os capitalistas (Barrett, 1988; Brenner, 2000).

A ideia da família como refúgio, que é sem dúvida uma idealização (Biroli, 2014a; Delphy e Leonard, 2004), também se complexifica quando se leva em conta as diferenças entre as mulheres. Quando a posição nas relações de trabalho fora da casa envolve exploração, alienação - e é impactada pelo racismo -, a vida familiar pode ter sentidos distintos. A ideia de que o trabalho remunerado libertaria as mulheres foi vista por feministas negras e provenientes das classes trabalhadoras como uma idealização fincada na experiência das poucas mulheres que podem ter acesso a carreiras profissionais com grau relativamente ampliado de autonomia e de remuneração. O trabalho assalariado "para as mulheres da classe trabalhadora que ganham muitas vezes menos do que o salário mínimo e recebem poucos benefícios, quando os recebem, significa a continuidade da exploração de classe" (Hooks, 1984:61). Como lembra Patrícia Hill Collins (2009), algo que é bastante evidente precisa ser levado em conta na construção da crítica feminista: muitas mulheres negras desempenham trabalho alienante não remunerado, como o trabalho doméstico sem fim das avós e mães solteiras, e remunerado, como o trabalho doméstico assalariado, o trabalho de lavar louças e passar roupas em restaurantes e lavanderias. O acesso a esse tipo de trabalho não assume, assim, cotidiana e historicamente, o mesmo sentido que o acesso ao trabalho pelas mulheres brancas que puderam trilhar carreiras profissionais. Nessas circunstâncias, a família 
pode funcionar como um dos poucos mecanismos de suporte para as pessoas, em que, "apesar do sexismo", é possível a experiência da dignidade e do valor próprio, "uma humanização que não é experienciada no mundo exterior, onde confrontamos todas as formas de opressão" (Hooks, 1984:38). Daí a crítica de que a "desvalorização da vida familiar na discussão feminista muitas vezes reflete a natureza de classe do movimento" (idem:39), deixando de fora essa dimensão das relações ${ }^{13}$.

Assim, o acesso ao trabalho remunerado se dá de forma diferenciada não apenas entre homens e mulheres, mas para diferentes grupos de mulheres. O mesmo ocorre no que diz respeito ao exercício de trabalho não remunerado dentro de casa e às formas que a dependência e vulnerabilidade poderão assumir no casamento ou quando este termina.

Os dados sobre renda e chefia familiar (Ipea, 2014, a partir dos dados da Pesquisa Nacional por Amostra de Domicílios [Pnad]) colaboram para confirmar essa interpretação. É crescente o número de mulheres na posição de chefes de família, isto é, de principais ou únicas responsáveis pela renda familiar. Em 1995, 22,9\% das famílias brasileiras tinham mulheres como chefes; em 2013, esse percentual havia subido para $38,8 \%$. A renda domiciliar per capita média dos domicílios em que o chefe de família é homem permanece, no entanto, superior. É 10,9\% maior do que a daqueles chefiados por mulheres. Entre os caminhos possíveis para a interpretação dessa desvantagem está o fato de que, entre as famílias chefiadas por mulheres, $42,6 \%$ são formadas por mulheres com seus filhos (contra 22,9\% formadas por casais com seus filhos). Já entre as famílias chefiadas por homens, apenas 3,6\% são formadas por homens com seus filhos (contra $57,3 \%$ formadas por casais com seus filhos).

Vale observar que mais da metade dos domicílios chefiados por mulheres tem à frente mulheres negras (53,7\%). Do ponto de vista dos arranjos familiares, são poucas as diferenças. O número de domicílios chefiados por mulheres que são formados por mulheres com seus filhos é pouco maior entre as mulheres negras, $17,7 \%$, do que entre as mulheres brancas, que perfaz $15,2 \%$. A maior diferença entre os dois grupos está na renda. Vale observar que o gap nesse caso é bem maior do que aquele existente entre a renda nos domicílios chefiados por mulheres e por homens, indicando que a questão racial se coloca como tema incontornável para o entendimento dessas assimetrias. Nos domicílios chefiados por mulheres brancas, a renda domiciliar per capita é 
$47,3 \%$ maior do que naqueles chefiados por mulheres negras - e $40 \%$ maior do que nos que são chefiados por homens negros (Ipea, 2014).

Esses dados parecem afastar a possibilidade de se compreender a vulnerabilidade relativa das mulheres como uma questão feminina. Em vez disso, parece necessário compreender a vulnerabilidade relativa de determinadas mulheres. A correlação entre trabalho não remunerado, trabalho remunerado e arranjos familiares tem efeitos distintos se consideramos as mulheres negras e as mulheres brancas. Embora a divisão sexual do trabalho permaneça ativa para os dois grupos $-87,6 \%$ das mulheres de 16 anos ou mais e $45,8 \%$ dos homens na mesma faixa etária dizem realizar trabalhos domésticos -, entre as mulheres com 10 anos de idade ou mais, o número médio de horas semanais dedicadas ao trabalho doméstico é de 23,8, mais do que o dobro do deles, que é de 10,1 horas (Ipea, 2014).

Em conjunto, esses dados indicam que o padrão atual de privatização das relações familiares, em que o apoio para as mulheres que têm filhos é precário, incide negativamente, sobretudo para as mulheres negras, que, no Brasil, estão mais concentradas entre os segmentos mais pobres da população.

As assimetrias entre mulheres e homens permanecem, mas se definem em conjunto com as variáveis de classe e de raça. O acesso à educação, que é maior entre as mulheres do que entre os homens no Brasil hoje, tem efeitos distintos para elas e para eles. A média de estudo entre as pessoas com mais de 15 anos era, em 2013, de 7,8 anos para os homens e de 8,2 para as mulheres. Quanto maior o nível de educação das mulheres, no entanto, maior é a diferença entre sua renda média e a dos homens (A. Araújo e Lombardi, 2013). Por outro lado, a diferença de estudo se amplia quando consideramos a raça. Entre os homens brancos na mesma faixa etária, ainda em 2013, a média é de 8,7 anos, entre os negros é de 6,9 anos; entre as mulheres brancas, é de 9 anos, enquanto entre as negras é de 7,4 (Ipea, 2014).

$\mathrm{O}$ acesso das mulheres a profissões de prestígio, assim como a presença maior de determinadas mulheres em ocupações marcadas pela precariedade, expõe essas formas cruzadas de desvantagem. A análise feita por Cristina Bruschini e Maria Rosa Lombardi (2000) sobre os dois polos da presença das mulheres no trabalho remunerado nos últimos anos do século XX mostra isso com clareza. Em um polo, o do trabalho doméstico, concentravam-se, em 1997, 18\% das mulheres empregadas. 
Também em 1997, 16\% das mulheres empregadas tinham ocupações que figuram entre as profissões técnicas, como a medicina, a arquitetu$\mathrm{ra}$, a engenharia, a advocacia e as carreiras jurídicas. Entre as primeiras, temos um perfil de mulheres jovens, de baixa escolaridade, realizando trabalho precário e pouco especializado caracterizado por longas rotinas de trabalho e baixa remuneração. Entre as profissionais das áreas técnicas, há também um grande percentual de mulheres jovens, o que é explicado pelo seu acesso recente comparativamente ao dos homens nessas profissões, o nível de escolarização é alto e os rendimentos são bastante superiores aos das mulheres do primeiro polo. Um elo uniria os dois polos: "é no trabalho das empregadas domésticas que as profissionais frequentemente irão se apoiar para poder se dedicar à própria carreira" (Bruschini e Lombardi, 2000:101).

Vale observar que, em 2013, ano em que foi aprovada pela primeira vez no Brasil legislação que equipara o trabalho doméstico remunerado a outros tipos de trabalho, o número de trabalhadoras domésticas havia se reduzido bastante relativamente a 1997, ano de referência dos dados discutidos por Bruschini e Lombardi ${ }^{14}$. O percentual de mulheres negras que exerciam trabalho doméstico era, no entanto, de 18,6\%, bastante próximo do percentual total das mulheres que exerciam trabalho doméstico remunerado em 1997, que era de $18 \%$. Já o de mulheres brancas era de 10,6\%. Vale observar também a questão da precariedade dos contratos nessa ocupação. Em 2009, aproximadamente uma em cada quatro mulheres no emprego doméstico tinha carteira assinada e 0,5\% delas, o que corresponde a cerca de 30 mil mulheres, não tinham renda própria, isto é, encontravam-se numa situação semelhante à de trabalho escravo (Ipea, 2011). Em 2013, apenas 31,8\% delas tinha carteira assinada, mas esse percentual fica abaixo dos $30 \%$ quando se considera apenas as mulheres negras e está abaixo dos $20 \%$ nas regiões Norte e Nordeste do país (Ipea, 2014).

A divisão sexual do trabalho está ancorada na naturalização de relações de autoridade e subordinação, que são apresentadas como fundadas na biologia e/ou justificadas racialmente. Em conjunto, restrições que se definem pelo gênero, pela raça e pela classe social conformam as escolhas, impõem desigualmente as responsabilidades e incitam a determinadas ocupações enquanto bloqueiam ou dificultam o acesso a outras.

A "atribuição de diferenças categoriais", que ocorre "por meio de referências a características corporais e, portanto, por meio de referências 
a supostas certezas biológicas" (Kerner, 2012:46) é ativada de diferentes maneiras. Está presente nas justificativas que romantizam os papéis, como no caso da ideologia maternalista - as mulheres cuidariam mais das crianças porque possuiriam tendências naturais para tal cuidado e não porque os homens são socialmente liberados dessa função. Está presente, também, na subalternização que é característica das ideologias racistas - as mulheres negras realizariam o trabalho remunerado de limpeza porque esta ocupação estaria de acordo com suas capacidades enquanto mulheres negras. No primeiro caso, serve para justificar assimetrias entre mulheres e homens; no segundo, para justificar assimetrias entre mulheres tanto quanto entre mulheres e homens.

Nesta seção, procurei expor o fato de que a produção do gênero na divisão do trabalho não se faz de maneira isolada em relação à classe e à raça. As desigualdades de gênero assim compreendidas constituem os limites da democracia. É esse o foco da próxima seção, que retoma mais diretamente a hipótese enunciada na introdução deste artigo, de que a divisão sexual do trabalho doméstico implica menor acesso das mulheres a tempo livre e a renda, com impacto nas suas possibilidades de participação política.

\section{DIVISÃO SEXUAL DO TRABALHO, GÊNERO E DEMOCRACIA}

A suspensão da divisão sexual do trabalho como problema político na ampla maioria das análises da democracia é correlata à invisibilidade, nessas análises, da posição das mulheres e, em especial, das relações de gênero. A abordagem restrita da democracia, em que a política é autonomizada relativamente ao cotidiano e às relações sociais, permite sua desconsideração. Ao mesmo tempo, a tendência contemporânea de "despolitização da teoria política" (Pateman, 2009:175-176, 198-199) contribui para eliminá-la como problema que exige reflexão. Alternativamente, em uma teoria política "politizada", atenta às disputas e hierarquias que conformam e limitam a democracia, ela ganharia lugar na problematização das formas aceitas de autoridade e de subordinação, assim como nas explicações sobre os limites à participação política mesmo que se trate dos limites à participação das mulheres, estamos falando de desvantagens que incidem sobre um contingente de pessoas que corresponde a mais da metade da população no caso brasileiro. 
As relações de autoridade que produzem a subordinação das mulheres são tecidas por múltiplos fatores. A dupla moral sexual, a tolerância à violência que as atinge por serem mulheres, a ideologia maternalista e os limites para o controle autônomo da sua capacidade reprodutiva são alguns deles. A divisão sexual do trabalho se apresenta como variável específica (ainda que não independente) que é determinante para a compreensão de como se organizam as hierarquias de gênero. Ela está presente, também, na composição dos outros fatores mencionados, ainda que as conexões não se estabeleçam sempre numa mesma direção, em que a primeira pudesse ser tomada como fundamento das demais, ou como causalidade direta. Tomemos como exemplo a violência doméstica: os obstáculos para que as mulheres deixem relacionamentos e lares violentos têm como componente importante, embora não exclusivo, o fato de que sua posição relativa implica, pelos padrões sociais expostos nas seções anteriores, condições materiais e cotidianas desvantajosas e de maior vulnerabilidade relativamente aos homens, sobretudo quando têm filhos pequenos.

A divisão sexual do trabalho tem caráter estruturante, como também procurei mostrar. Ela não é a expressão das escolhas de mulheres e homens, mas constitui estruturas que são ativadas pela responsabilização desigual de umas e outros pelo trabalho doméstico, definindo condições favoráveis à sua reprodução. Essas estruturas constituem as possibilidades de ação, na medida em que constrangem as alternativas, incitam julgamentos que são apresentados como baseados na natureza (em aptidões e tendências que seriam naturais a mulheres e homens) e fundamentam formas de organização da vida que, apresentando-se como naturais ou necessárias, alimentam essas mesmas estruturas, garantindo assim sua reprodução.

Por isso entendo que a divisão sexual do trabalho é produtora do gênero, ainda que não o seja isoladamente. Ela compõe, de forma destacada, as dinâmicas que dão forma à dualidade feminino-masculino, ao mesmo tempo que posiciona as mulheres de maneira desigual segundo classe e raça.

A análise de sua relação com a democracia, aqui proposta, é orientada pelas seguintes premissas, decorrentes das abordagens teóricas e questões empíricas discutidas antes neste artigo: 
1) a divisão sexual do trabalho não pode ser explicada no âmbito da individualidade, das escolhas voluntárias dos indivíduos - ela as conforma, em vez de resultar delas;

2) a divisão sexual do trabalho é estruturante das identidades e alternativas. Nessa condição, é ativada pelas instituições, pelas políticas públicas (ou pela ausência de certas políticas) e, em conexão com elas, pelas formas simbólicas de afirmação do feminino e do masculino que se definem em outras dimensões das relações de gênero.

3) a divisão sexual do trabalho constitui privilégios - para os homens e entre as mulheres - de modo que interfere diretamente nas condições de acesso a tempo livre, remuneração, redes de contato e no reconhecimento de competências e habilidades. Em consequência, interfere nas condições para tomar parte do debate público e atuar nos espaços da política institucional.

A subinclusão (Crenshaw, 2002) da divisão sexual do trabalho na agenda política e na agenda das teorias da democracia pode ser atribuída a dois fatores.

Começo pelo primeiro fator, que se organiza nas assimetrias entre mulheres e homens. Para os homens, que são maioria na política institucional (na Câmara dos Deputados, no Brasil, eles têm sido cerca de $90 \%$ dos parlamentares $)^{15}$, a carga desigual produzida pela divisão sexual do trabalho e a precariedade no exercício do trabalho doméstico remunerado não são em geral problemas. Passam longe da sua experiência, não se definindo assim como questões que os tocam diretamente. Por serem, em sua maioria, não homens genéricos, mas homens brancos pertencentes aos estratos com maior remuneração média e maior escolaridade, sua experiência, que é diferente daquela das mulheres que realizam cotidianamente o trabalho doméstico, é ainda mais distante quando se toma como referência, por exemplo, as mulheres que realizam trabalho doméstico remunerado. Dizendo de maneira bastante resumida, suas características os situam na posição de quem exerce menos trabalho doméstico por ser homem e na posição de patrão nas relações de trabalho doméstico remunerado.

Os dados já apresentados sobre tempo médio semanal dedicado ao trabalho doméstico são significativos. A correlação entre ocupação remunerada e cuidado com os filhos também reforça esse raciocínio, considerando as implicações para as mulheres da responsabilização 
desigual pela vida cotidiana. Em 2012, somente 20,3\% das mulheres com filhos de até 3 anos de idade tinham todos eles em creche. Entre as que tinham todos seus filhos em creche, $72,9 \%$ estavam ocupadas, número que cai para $42,6 \%$ quando se observa aquelas que não tinham qualquer das/os filhas/os em creche (Raseam, 2015).

Para elas, que, como vimos, dedicam mais do que o dobro de destinado por eles ao trabalho doméstico e são responsabilizadas prioritariamente pelas crianças, e não para eles, que são, no entanto, os que têm maior acesso aos espaços decisórios, a disponibilidade de creches é uma questão fundamental. A agenda política pode, assim, ser profundamente enviesada quando as mulheres não têm acesso igualitário à definição coletiva e à expressão pública de suas necessidades e interesses, sobretudo nos espaços em que necessidades e interesses podem desdobrar-se em agenda e exercício de influência.

O segundo fator se organiza nas assimetrias entre mulheres, tanto quanto entre mulheres e homens. O conjunto de problemas que a divisão do trabalho suscita, nesse caso, pode ter baixa prioridade não apenas para os homens, mas também para muitas mulheres. Para um grupo determinado de mulheres, ele pode não assumir a forma de obstáculo para sua atuação na vida pública quando é possível contratar o trabalho doméstico remunerado de outras mulheres. Nessa condição, os problemas não estão suspensos (mesmo as mulheres em posição vantajosa dedicam maior tempo aos afazeres domésticos do que os homens, como visto), mas têm seu impacto reduzido pelo acesso a produtos e pela contratação dos serviços de outras mulheres. Por isso, podem não ser "percebido[s] como um problema de gênero porque não faz[em] parte da experiência das mulheres dos grupos dominantes" (Crenshaw, 2002:176). Embora sejam minoria entre as mulheres, são maioria entre aquelas que têm, em minoria e enfrentando também obstáculos, ocupado cargos políticos.

Este é, parece-me, um ponto fundamental para compreender tanto seu impacto diferenciado quanto a pouca atenção dada a sua relação com os limites das democracias: a divisão sexual do trabalho existe na forma de privilégio, tanto quanto na de desvantagem e opressão. Nas relações que são assim estabelecidas, estão no polo do privilégio aqueles (homens, mas também mulheres, embora em posições relativas distintas, mesmo quando fazem parte de uma mesma classe social) que têm presença ampliada na política institucional e, como tal, maiores possi- 
bilidades de influenciar a agenda pública e a formulação de leis e políticas. Existe na forma de desvantagem e opressão justamente para quem tem menores possibilidades de ocupar espaços e exercer influência no sistema político (mulheres, em especial mulheres negras e pobres).

Em outras palavras, quanto mais a divisão sexual do trabalho doméstico incide como problema e obstáculo na vida das pessoas, mais distantes elas estão do sistema político. Quanto mais envolvidas estão com o trabalho doméstico cotidiano, menores e menos efetivos são os instrumentos de que dispõem para politizar as desvantagens que vivenciam e as hierarquias assim estruturadas.

Para quem não realiza trabalho doméstico, a ideia de que toma tempo e restringe outras formas de atuação na sociedade pode não ser evidente. Podemos entender que se configura na divisão sexual do trabalho uma forma do que Joan Tronto (2013:58) definiu como "irresponsabilidade dos privilegiados". Por terem sua condição vantajosa aceita previamente, algumas pessoas podem operar como se não fosse uma vantagem. Um exemplo é que aqueles que nunca terão que se preocupar com a limpeza cotidiana da casa ou do ambiente de trabalho podem tratá-la como irrelevante ou simplesmente não enxergá-la, e ela continuará a ser feita, de maneira que, de fato, para eles, não exige tempo, esforço e energia. As relações são estruturadas de modo que os libera da carga das responsabilidades atribuídas a outras pessoas. Sua experiência é tão distinta daquelas para quem essas relações implicam desvantagens que podem operar como se essas desvantagens não existissem.

Tronto (idem) alerta para o fato de que esse mecanismo é simultaneamente moral e político. De uma perspectiva moral, algumas pessoas podem liberar-se das responsabilidades alegando que suas responsabilidades seriam de outro tipo (e, acrescento, superiores, dada a desvalorização do trabalho do qual estão sendo liberados e a sobrevalorização do trabalho que exercem); de uma perspectiva política, algumas pessoas podem atribuir, a outras, responsabilidades sem ter que justificar essa atribuição desigual ou a alocação também desigual de recursos que ela implica.

A divisão sexual do trabalho não produz sozinha o acesso desigual ao sistema político, mas é um dos seus "gargalos". A seguir, elenco alguns dos obstáculos para a participação política das mulheres que têm cone- 
xão com a divisão sexual do trabalho, sem qualquer intenção de esgotá-los neste $\operatorname{artigo}^{16}$.

As mulheres atuam politicamente a despeito da divisão sexual do trabalho. Mas o custo dessa atuação é, para elas, ampliado. Isso se dá na forma de julgamentos e pressões sociais, que implicam maiores dificuldades para a manutenção de relacionamentos ${ }^{17}$ uma vez que o trabalho político exige uma rotina que contrasta com as expectativas correntes de cuidado dos filhos e responsabilidade cotidiana pela vida doméstica.

Apresenta-se, também, na forma de restrições concretas no acesso a tempo, uma vez que se espera delas - mas não deles - que o envolvimento com sindicatos, militância, partidos políticos e mesmo sua carreira seja equilibrado com a vida doméstica familiar. A divisão sexual do trabalho consome tempo desigualmente de mulheres e homens. Ainda que isso se dê de forma assimétrica entre as mulheres, pelas razões já discutidas, pode ser tomada como um fator para a explicação da menor participação política das mulheres, para sua posição de grupo sub-representado na política.

Essa mesma dinâmica, de responsabilização desigual e restrições no acesso a tempo, sobretudo quando as mulheres têm filhos pequenos, constrange e orienta sua presença no mercado de trabalho e seu acesso a renda. Como visto neste artigo, os homens têm renda maior do que a das mulheres, mesmo em um contexto em que o acesso delas ao ensino é maior do que o deles. Entre elas, o acesso a ocupações remuneradas tem correlação com a presença ou não dos filhos em creches, como também foi mencionado anteriormente.

Ainda uma vez, essa dinâmica, em que as mulheres têm menor tempo, menos recursos (e, sistematicamente, mais tarefas domésticas cotidianas), pode também reduzir o acesso a redes de contato que amplificariam as possibilidades de construção de uma carreira política e mesmo de acesso a movimentos e espaços de organização coletiva.

Vale destacar que, em conjunto, as variáveis consideradas reduzem as possibilidades de transposição da atuação política cotidiana, no âmbito local, comunitário, assim como nos movimentos sociais, para a política eleitoral e para outras formas do exercício direto de influência política.

Em conjunto, fatores que podemos entender como ideológicos, como a naturalização das competências e habilidades, e fatores materiais e da 
ordem do acesso assimétrico a recursos, como a remuneração desigual e o acesso também desigual a tempo livre, funcionam como estímulos ou desestímulos à participação na vida pública e, especificamente, na política. A dimensão ideológica e a dimensão material/de recursos se complementam. A remuneração pelo trabalho se define numa escala em que o que é historicamente associado ao feminino tem menor valor; o acesso a tempo, por sua vez, se organiza distintamente pela naturalização de determinadas responsabilidades como femininas e/ou maternas.

Há, assim, elementos suficientes para que a conexão entre divisão sexual do trabalho e democracia seja considerada e, ao menos, colocada na posição de hipótese ou testada em pesquisas teóricas e empíricas.

\section{CONSIDERAÇÕES FINAIS}

A análise do trabalho realizado na esfera familiar evidencia as hierarquias que organizam as relações dentro e fora dela. Daí a importância de que essas perguntas sejam parte das indagações feitas por pesquisadoras e pesquisadores que analisam as desigualdades sociais e a democracia: quem produz, quem cuida? Como se define a partilha do tempo e da energia entre trabalho remunerado e não remunerado?

Essas perguntas estão diretamente ligadas àquelas que, segundo Sylvia Walby (1990: 25), estão na base dos estudos de gênero e trabalho: por que as mulheres tipicamente ganham menos do que os homens? Por que as mulheres se engajam menos em trabalho remunerado do que os homens? Por que as mulheres têm ocupações diferentes das dos homens?

A conexão que destaco neste artigo é, por sua vez, entre os problemas que assim se definem e os limites da participação política nas democracias. Entendo que as perguntas acima são necessárias para que se possa responder adequadamente a outra: por que as mulheres têm menor presença na política institucional, vendo assim reduzida sua capacidade de influência, como grupo, relativamente aos homens?

A disputa pelos limites do que é e do que não é político é um dos pontos principais de conflito sociopolítico no capitalismo tardio (Fraser, 2013:60). Ela é marcada pela compreensão, hegemônica na Ciência Política e no pensamento político em sentido mais amplo, de que a políti- 
ca é uma esfera distinta e antagônica relativamente à vida doméstica e ao mercado, que constituiriam esferas privadas.

Os movimentos feministas, assim como os movimentos antirracistas, vêm tendo um papel nessas disputas justamente ao colocar em xeque as fronteiras entre o que é e o que não é político (Miguel e Biroli, 2014). Tiveram sucesso historicamente em muitas frentes, mas esse sucesso depende de um longo processo de ressemantização das hierarquias e opressões cotidianas, para o qual contam com menos recursos (discursivos, materiais e na forma de posições no sistema político) do que os grupos privilegiados.

Ainda com Fraser (2013), o ponto aqui é que a diversidade de públicos não implica que tenham as mesmas condições de fazer valer suas experiências, como a base para necessidades e interesses que ganhem significado a partir desses mesmos grupos e sejam definidos como políticos, isto é, como pontos fulcrais para as disputas em torno de direitos e recursos. As mulheres, sobretudo as negras e as mais pobres, têm menos poder para politizar suas necessidades e interesses - o que não significa que não o façam, mas, como dito anteriormente, esse caminho é mais longo, mais difícil e se define em desvantagem relativamente aos grupos que detêm recursos para fazer valer os seus direitos junto ao Estado e no debate público ${ }^{18}$.

Tem sentido, parece-me, distinguir algumas dimensões nessas disputas. Uma delas é a posição relativa dos grupos na determinação de quais necessidades e interesses entram na agenda pública. Outra dimensão corresponde à disputa por conferir sentido às necessidades reconhecidas, que adentraram o debate e a agenda política. Nesse caso,é fundamental se os grupos ocupam a posição de agentes autônomos, vistos como capazes de conferir sentido a suas necessidades e buscar alternativas para atendê-las, ou se estão na posição de objetos de políticas, vistos como passivos por outros agentes (políticos, religiosos, técnicos) que dariam então sentido legitimamente a suas necessidades e participariam da construção das políticas para atendê-las.

Podemos entender que algumas das temáticas discutidas neste artigo vêm ganhando relevância no debate público e na agenda política, nas últimas décadas, mas em um quadro de disputas nos quais predominam visões que não conferem autonomia às mulheres como agentes políticos e colaboram para suspender a divisão sexual do trabalho como um problema. Na forma da preocupação com a família, podem 
ganhar força políticas que colaboram para aprofundar privilégios e desvantagens existentes. O apelo é, nesse caso, a um modo de organização familiar nuclear privada que pressupõe a liberação dos homens do trabalho doméstico cotidiano, reforçando a autoridade masculina pelo trânsito potencialmente maior na vida pública, enquanto as mulheres são julgadas, tendo como referência seu papel como mães. Ao mesmo tempo, as responsabilidades públicas são reduzidas e a dinâmica de mercado ganha maior espaço na solução dos problemas cotidianos, ampliando a precariedade de quem tem menos recursos.

Quando a ideologia familista é a resposta para os problemas relacionados ao cuidado das crianças, que é parte significativa do trabalho cotidiano das mulheres, aprofunda-se a exclusão destas da vida pública (Brenner, 2000:108). A vulnerabilidade relativa das mulheres solteiras, por exemplo, pode ser vista não como um fator das assimetrias aqui discutidas, mas como uma derivação de problemas morais associados ao que é, nesse caso, visto como o declínio da família. Em oposição à politização que os movimentos feministas vêm promovendo historicamente, assim como às transformações sociais que ampliaram a possibilidade de que as mulheres atuem publicamente, esse tipo de conservadorismo assume a forma da reprivatização (Fraser, 2013).

A participação na política institucional amplia os recursos para a politização e ressemantização das experiências e dos problemas enfrentados pelas pessoas. Trata-se de um âmbito privilegiado das disputas, em que se definem quais são as necessidades prioritárias e o que seria preciso para atendê-las, assim como para a construção coletiva e validação política dos interesses.

A exclusão sistemática de alguns grupos expõe o caráter hierarquizado da democracia, mantendo-os numa condição de sub-representação e de marginalidade no debate público, na construção de normas e políticas públicas. Procurei mostrar que a divisão sexual do trabalho é um fator importante dessa exclusão, comprometendo a autonomia individual e coletiva das mulheres. Ainda que não incida na mesma forma e grau na vida de todas as mulheres, estabelece assimetrias no acesso a tempo, renda e redes de contato, assim como na forma de julgamentos e pressões sociais.

As restrições que assim se estabelecem se definem na forma de opressões cruzadas, isto é, na convergência entre gênero, classe e raça. Sem que se leve em conta as relações de gênero, é impossível explicar por- 
que a precariedade e a vulnerabilidade são maiores entre as mulheres do que entre os homens. Sem que se leve em conta as relações de classe e de raça, é impossível compreender porque as mulheres estão em posições assimétricas nas hierarquias que assim se definem.

Permanece, assim, a necessidade de se compreender e enfrentar os padrões de gênero nessas hierarquias, levando em conta que a produção do gêenero nas relações de trabalho se faz na interseção entre gênero, classe e raça. Este artigo teve como objetivo contribuir para essa tarefa, destacando os elos entre a produção do gênero nas relações de trabalho e a democracia. Contesta, assim, concepções autonomizadas da política, que a isolam do cotidiano da vida social.

O foco no cotidiano, nesse caso pelo prisma da divisão sexual do trabalho e de seus efeitos, não implica uma menor atenção à política institucional. Procurei ressaltar que não se trata de anular a importância do acesso ao sistema político, isto é, da participação nas arenas da política representativa, em sua delimitação mais restrita. Meu objetivo foi, assim, colaborar para a construção de modelos teóricos, informados empiricamente, que incorporem uma dimensão estrutural fundamental das relações de gênero - a divisão sexual do trabalho - à análise crítica dos limites da democracia. A sub-representação das mulheres na política institucional expõe esses limites. A dinâmica que a produz, por sua vez, não pode ser explicada sem uma crítica aguda da vida cotidiana e dos padrões sociopolíticos que nela se escoram.

(Recebido para publicação em novembro de 2015)

(Reapresentado em agosto de 2016)

(Aprovado para publicação em setembro de 2016) 


\section{NOTAS}

1. Para a noção de autonomia decisória, cf. Cohen (1997). Para análises anteriores em que assumo essa direção, cf. Biroli (2013; 2014b).

2. Uma busca exploratória em periódicos brasileiros que fazem parte da base de periódicos SciELO, considerando periódicos qualificados como A1, A2 e B1 na área de Ciência Política, indica que são escassas as publicações. A título de exemplo, quando se faz a busca pela expressão "trabalho doméstico", como assunto, o resultado é de "zero" artigo para Brazilian Political Science Review, DADOS - Revista de Ciências Sociais, Lua Nova e Revista de Sociologia e Política e de dois artigos para Revista Brasileira de Ciência Política e Revista Brasileira de Ciências Sociais. Quando a busca é feita com as palavras "trabalho e gênero", em todos os índices (em vez de apenas em assunto), retorna "zero" artigo para Brazilian Political Science Review, 2 para DADOS - Revista de Ciências Sociais e Revista de Sociologia e Política, 3 para Lua Nova, 8 para Revista Brasileira de Ciência Política e 10 para Revista Brasileira de Ciências Sociais (a consulta à base www.scielo.br foi realizada em 5 de agosto de 2016). Uma busca mais sistemática teria que levar em conta também a área disciplinar de atuação e de formação das(os) autoras(es).

3. São três dossiês. Foram publicados na revista Pagu em 2002 e em 2009, organizados, respectivamente, por Ângela Araújo Carneiro e por Nadya Araújo Guimarães, que também foi a organizadora de um dossiê na revista Estudos Feministas em 2004. Neves (2013) menciona um dossiê da revista Sociologias do ano 2000, mas, embora a relação entre trabalho e gênero apareça em alguns textos, ela não é central ao dossiê nem aos artigos. Um exemplo da produção continuada de pesquisas sobre o tema no Brasil é o da equipe de pesquisadoras da Fundação Carlos Chagas. Entre suas contribuições está o Banco de dados sobre o trabalho das mulheres (disponível em http:/ / www.fcc.org.br/bdmulheres/index.php?area=home).

4. A busca foi feita em setembro de 2015, quando estavam disponíveis no SciELO (www.scielo.org.br) 41 números da revista Estudos Feministas, publicados entre 2001 e 2015, e 28 números da revista Pagu, publicados no mesmo período.

5. Todas as citações de textos em língua estrangeira têm tradução livre.

6. Para ela, essa ideologia precede o capitalismo, mas foi ativamente incorporada não apenas pelos capitalistas, como também pelos trabalhadores organizados. A aposta em um salário capaz de sustentar a família para os homens, em vez da luta pela elevação de todos os salários, é uma das formas mais explícitas dessa incorporação. A afirmação de diferenças nas habilidades teve, também, um papel na divisão do trabalho, que dispõe hierarquias - que são ao mesmo tempo de valorização de atividades e das pessoas que as realizam - segundo o gênero (Barrett, 1988, cf. em especial pp. 167-172).

7. Na análise da adesão das mulheres a práticas e valores que compõem a dinâmica que as oprime, as teorias feministas contribuíram para um entendimento mais complexo de como são produzidas as preferências e como se efetivam as escolhas. Discuti isso em outro lugar (Biroli, 2013), ressaltando as condições sociais em que as escolhas são feitas e os processos, materiais e simbólicos, nos quais as preferências que as justificam são produzidas. 
8. O conjunto completo dos argumentos que elenca na sua crítica aos sistemas duais está em Walby (1990:40). Seu diálogo crítico mais específico é com a posição de Heidi Hartmann $(1981,1997)$, para quem, no capitalismo, um sistema de controle mais direto e pessoal, característico do patriarcado, teria sido recodificado em um sistema mediado por instituições sociais (Hartmann, 1997:207).

9. Uma das razões dessa opção está fora do foco deste texto, mas é importante na minha compreensão e em parte significativa das contribuições que as teorias feministas apresentam para a análise da democracia: a construção da dependência como problema a ser superado pode impedir que se tenha clareza de suas formas incontornáveis, colaborando para suspendê-las e defini-las como questões privadas. Parece-me necessário incorporar a dependência como um fato da vida, ao mesmo tempo que se tem a autonomia como valor de referência (cf. Biroli, 2013, 2014b, 2015).

10. Para um mapeamento de como o debate sobre as convergências entre gênero, classe e raça se apresenta no debate feminista, cf. Biroli e Miguel (2015).

11. Por isso é importante levar em conta o papel das ideologias naturalistas na retração das conquistas do feminismo em um contexto em que o exercício aberto da autoridade dos homens sobre as mulheres perdeu legitimidade (cf. Badinter, 2011).

12. Vale cf. a análise de Dorothy Roberts (1997) sobre a relação entre racismo e controle da capacidade reprodutiva das mulheres.

13. Por outro lado, ainda que a maioria das mulheres não tenha empregos satisfatórios, tomar parte da esfera pública por meio da inserção no mundo do trabalho em vez de permanecer na rotina de isolamento e trabalho doméstico repetitivo é considerado por muitas delas um bem (Davis, 1983: 242; Sarti, 2011:100; essa discussão está presente também em Miguel e Biroli, 2014).

14. Desde 2009, a Pnad do Instituto Brasileiro de Geografia e Estatística (IBGE) mostrava uma queda lenta, mas ininterrupta no número de mulheres que realizam trabalho doméstico remunerado. Em 2013, esse número era de 5.963.976, 11,6\% menor do que em 2009, quando era de 6.750.416. Mas essa tendência pode estar se revertendo - a Pnad Contínua divulgada pelo IBGE mostra que esse número ultrapassou novamente o de 6 milhões de mulheres empregadas em trabalho doméstico no primeiro trimestre de 2015.

15. O paralelo com a produção acadêmica é, mais uma vez, perfeitamente possível. A subinclusão da divisão sexual do trabalho na agenda política se dá de forma correlata a sua subinclusão na agenda dos estudos acadêmicos sobre democracia.

16. Para um mapeamento das análises sobre esses obstáculos, cf. C. Araújo e Alves (2007) e Miguel e Biroli (2011).

17. As entrevistas feitas por Souza (2014) com as deputadas capixabas mostram isso claramente.

18. Nessa análise, ela distingue preliminarmente - embora desenvolva pouco - entre o recurso a registros discursivos que se organizam em termos de necessidade, de direitos e de interesses, que seriam os três "idiomas reconhecidos nos quais se pode fazer reivindicações" (Fraser, 2013:57). Aqui, trato de necessidades e interesses conjuntamente, de modo que não os coloco como intercambiáveis, mas também não problematizo as duas noções e suas implicações na análise do contexto contemporâneo das disputas nas democracias. 


\section{REFERÊNCIAS BIBLIOGRÁFICAS}

ARAÚJO, Ângela M. C.; LOMBARDI, Maria Rosa. (2013), “Trabalho Informal, Gênero e Raça no Brasil do Início do Século XXI". Cadernos de Pesquisa, vol. 43, pp. 452-477.

ARAÚJO, Clara; ALVES, José Eustáquio Diniz. (2007), “Impactos de Indicadores Sociais e do Sistema Eleitoral sobre as Chances das Mulheres nas Eleições e suas Interações com as Cotas". DADOS - Revista de Ciências Sociais, vol. 50, no 3, pp. 535-577.

ARAÚJO, Clara; SCALON, Celi. (2006), "Gênero e a Distância entre a Intenção e o Gesto". Revista Brasileira de Ciências Sociais, vol. 21, no 62, pp. 45-68.

BADINTER, Elizabeth. (1985) [1980], O Amor Incerto: História do Amor Maternal do Século XVII ao Século XX. Lisboa, Relógio D'Água.

. (2011) [2010], O Conflito: A Mulher e a Mãe. Rio de Janeiro, Record.

BARRETT, Michèle. (1988) [1980], Women's Opression Today: The Marxist/Feminist Encounter. London, Verso.

BIROLI, Flávia. (2013), Autonomia e Desigualdades de Gênero: Contribuições do Feminismo para a Crítica Democrática. Niterói, Eduff.

(2014a), Família: Novos Conceitos. São Paulo, Perseu Abramo.

(2014b), "Autonomia e Política no Debate Teórico sobre Aborto: Implicações Teóricas e Políticas". Revista Brasileira de Ciência Política, no 15, pp. 37-68.

. (2015), “Responsabilidades, Cuidado e Democracia". Revista Brasileira de Ciência Política, no 18, pp. 81-117.

; MIGUEL, Luis Felipe. (2015), "Gênero, Raça, Classe: Dominações Cruzadas e Convergências na Reprodução das Desigualdades". Mediações, vol. 20, no 2, pp. 27-55.

BRENNER, Johanna. (2000), Women and the Politics of Class. New York, Monthly Review Press.

BRUSCHINI, Cristina. (1994), "Trabalho Feminino: Trajetória de um Tema, Perspectiva para o Futuro". Estudos Feministas, vol. 2, no 3, pp. 17-32.

(2006), “Trabalho Doméstico: Inatividade Econômica ou Trabalho Não-remunerado?". Revista Brasileira de Estudos Populacionais, vol. 23, no 2, pp. 331-353.

; LOMBARDI, Maria Rosa. (2000), “A Bipolaridade do Trabalho Feminino no Brasil Contemporâneo". Cadernos de Pesquisa, no 110, pp. 67-104.

. (2001/2002), “Instruídas e Trabalhadeiras: Trabalho Feminino no Final do Século XX". Cadernos Pagu, nos 17/18, pp. 157-196.

CARNEIRO, Sueli. (2011), Racismo, Sexismo e Desigualdade no Brasil. São Paulo, Selo Negro.

COHEN, Jean. (1997), "Rethinking Privacy: Autonomy, Identity, and the Abortion Controversy", in J. Weintraub; K. Kumar (eds.), Public and Private in Thought and Practice. Chicago, The University of Chicago Press. 
CRENSHAW, Kimberlé. (2002), “Documento para o Encontro de Especialistas em Aspectos da Discriminação Racial Relativos ao Gênero". Revista Estudos Feministas, vol. 10, no 1, pp. 171-188.

COLLINS, Patricia Hill. (2009) [2000], Black Feminist Thought. New York/London, Routledge.

DAVIS, Angela Y. (1983) [1981], Women, Race, E Class. New York, Vintage.

DELPHY, Christine. (2013a) [1997], L'Ennemi Principal. 1. Économie Politique du Patriarcat. Paris, Éditions Syllepse. . (2013b) [2001], L'Ennemi Principal. 2. Penser le Genre. Paris, Éditions Syllepse.

; LEONARD, Diana. (2004) [1992], Familiar Exploitation: A New Analysis on Marriage in Contemporary Western Societies. Cambridge, Polity Press.

FRASER, Nancy. (2013), Fortunes of Feminism: From State-managed Capitalism to Neoliberal Crisis. New York, Verso.

FRIEDAN, Betty. (2001) [1963], The Feminine Mystique. New York, Norton.

FUNDAÇÃO CARLOS CHAGAS. (s/d), Banco de Dados sobre o Trabalho das Mulheres. Disponível em: http://www.fcc.org.br/bdmulheres/. Acessado em agosto de 2015.

HARTMANN, Heidi. (1981), "The Family as the Locus of Gender, Class and Political Struggle: The Example of Housework". Signs, vol. 3, no 6, pp. 366-394.

. (1997), “The Unhappy Marriage of Marxism and Feminism: Towards a more Progressive Union", in L. Nicolson (ed.), The Second Wave: A Reader in Feminist Theory. New York, Routledge.

HIRATA, Helena; KERGOAT, Danièle. (2007), “Novas Configurações da Divisão Sexual do Trabalho". Cadernos de Pesquisa, vol. 37, no 132, pp. 595-609.

HOOKS, Bell. (1984), Feminist Theory: From Margin to Center. (2a ed.). New York/Boston, South End Press.

IBGE (Instituto Brasileiro de Geografia e Estatística). (2013), Pesquisa Nacional por Amostra de Domicílios 2012: Síntese de Indicadores. Rio de Janeiro, IBGE.

IPEA (Instituto de Pesquisa Econômica Aplicada). (2011), Retrato das Desigualdades de Gênero e Raça. (4a ed.). Brasília, Ipea.

. (2014), Retrato das Desigualdades de Gênero e Raça. Brasília, Ipea. Disponível em http://www.ipea.gov.br/retrato/indicadores.html. Acessado em setembro de 2015.

KERGOAT, Danièle. (1982), Les Ouvrières. Paris, Le Sycomore.

. (2010), “Dinâmica e Consubstancialidade das Relações Sociais". Novos Estudos, no 86, pp. 93-103.

KERNER, Ina. (2012), “Tudo é interseccional?”. Novos Estudos, no 93, pp. 45-58.

MIGUEL, Luis Felipe; BIROLI, Flávia. (2011), Caleidoscópio Convexo: Mulheres, Política e Mídia. São Paulo, Unesp. (2014), Feminismo e Política: Uma Introdução. São Paulo, Boitempo Editorial.

DADOS - Revista de Ciências Sociais, Rio de Janeiro, vol. 59, nº 3, 2016 


\section{Flávia Biroli}

NEVES, Magda. (2013), "Anotações sobre Gênero e Trabalho". Cadernos de Pesquisa, vol. 43, no 149, pp. 404-421.

PATEMAN, Carole. (1985) [1979], The Problem of Political Obligation: A Critique of Liberal Theory. Berkeley, University of California Press.

. (2009) [2002], “Soberania Individual e Propriedade na Pessoa”. Revista Brasileira de Ciência Política, no 1, pp. 171-218.

PINTO, Céli Regina Jardim. (2010), “Feminismo, História e Poder”. Revista de Sociologia e Política, vol. 18, no 36, pp. 15-23.

RASEAM. (2015), Relatório Anual Socioeconômico da Mulher, 2014. Brasília, Secretaria de Políticas para Mulheres.

ROBERTS, Dorothy. (1997), Killing the Black Body: Race, Reproduction, and the Meaning of Liberty. New York, Pantheon.

SAFFIOTI, Heleieth. (2013) [1969], A Mulher na Sociedade de Classes: Mito e Realidade. (3a ed.). São Paulo, Expressão Popular.

SARTI, Cynthia. (2011), A Família como Espelho: Um Estudo sobre a Moral dos Pobres. (7ạ ed.). São Paulo, Cortez.

SOUZA, Dayane Santos de. (2014), Entre o Espírito Santo e Brasília: Mulheres, Carreira Política e o Legislativo Brasileiro a partir da Democratização. Dissertação (Mestrado em Ciências Sociais), Universidade Federal do Espírito Santo, Vitória.

SOUZA-LOBO, Elizabeth. (1991), A Classe Operária Tem Dois Sexos: Trabalho, Dominação e Resistência. São Paulo, Brasiliense.

SPELMAN, Elizabeth. (1988), Inessential Woman: Problems of Exclusion in Feminist Thought. Boston, Beacon Press.

TRONTO, Joan C. (2013), Caring Democracy: Markets, Equality, and Justice. New York, New York University Press.

WALBY, Sylvia. (1990), Theorizing Patriarchy. Oxford, Basil Blackwell.

WILLIAMS, Joan C. (2010), Reshaping the Work-family Debate: Why Men and Class Matter. Cambridge, Harvard University Press.

YOUNG, Iris Marion. (1997), Intersecting Voices: Dilemmas of Gender, Political Philosophy, and Policy. Princeton, Princeton University Press. 


\section{RESUMO}

\section{Divisão Sexual do Trabalho e Democracia}

O objetivo deste artigo é analisar as conexões entre a divisão sexual do trabalho, aqui entendida como um fator fundamental na produção do gênero, e os limites das democracias contemporâneas. A análise se apoia em extensa literatura sobre o tema, acompanhada de aporte empírico que permite situar a discussão no contexto brasileiro. É orientada por dois axiomas e uma hipótese, aos quais correspondem as três principais seções do artigo: (A1) a divisão sexual do trabalho está na base das hierarquias de gênero nas sociedades contemporâneas; (A2) essas hierarquias assumem formas diferenciadas segundo a posição de classe e raça das mulheres; $(\mathrm{H})$ as assimetrias assim constituídas, entre as quais se destacam o acesso desigual a tempo livre e a renda, limitam a participação política das mulheres. O reconhecimento do impacto da divisão sexual do trabalho se faz em uma concepção ampliada da política, que leva em conta as relações de poder no cotidiano. A análise destaca como essas relações incidem no acesso ao sistema político. Procura, com isso, colaborar para a construção de modelos teóricos que incorporem essa dimensão fundamental das relações de gênero, a divisão sexual do trabalho, à análise crítica dos limites da democracia.

Palavras-chave: divisão sexual do trabalho; democracia; desigualdades; gênero

\section{ABSTRACT \\ The Sexual Division of Labor and Democracy}

The aim of this article is to analyze the connections between the sexual division of labor, understood here as a fundamental factor in the production of gender, and the limits of contemporary democracies. The analysis is supported by extensive literature on the subject, accompanied by empirical contributions that allow us to situate the discussion in the Brazilian context. Two axioms and one guiding hypothesis form the three main sections of the article, as follows: (A1) the sexual division of labor is at the heart of gender hierarchies in contemporary societies; (A2) these hierarchies assume different forms according to women's class and race; $(\mathrm{H})$ the resultant discrepancies particularly in the form of unequal access to leisure time and income - restrict women's political participation. Recognition of the impact of the sexual division of labor is made according to a broad vision of politics that takes into account everyday power relations. The analysis highlights how these relations combine to affect access to the political system, in order to help construct theoretical models that incorporate this fundamental dimension of gender relations, the sexual division of labor, and the critical analysis of the limits of democracy.

Key words: the sexual division of labor; democracy; inequality; gender 


\section{RÉSUMÉ}

\section{Division Sexuelle du Travail et Démocratie}

L'objectif de cet article est d'analyser les connexions entre la division sexuelle $\mathrm{du}$ travail, ici entendue comme un facteur fondamental de la production $\mathrm{du}$ genre, et les limites des démocraties contemporaines. Notre analyse s'appuie sur l'abondante littérature du domaine et sur un apport empirique permettant de situer le débat dans le contexte brésilien. Nous avons émis deux axiomes et une hypothèse correspondant aux trois principales parties de cet article: (A1) la division sexuelle du travail est à la base des hiérarchies de genre dans les sociétés contemporaines; (A2) ces hiérarchies assument des formes différenciées en fonction de la position de classe et de l'origine ethnique des femmes; $(\mathrm{H})$ les asymétries ainsi constituées, parmi lesquelles se distinguent l'accès inégal au temps libre et au revenu, limitent la participation politique des femmes. La reconnaissance de l'impact de la division sexuelle du travail implique une conception élargie de la politique qui prenne en compte les rapports de pouvoir au quotidien. Notre analyse souligne la manière dont ces relations jouent sur l'accès au système politique. Il s'agit ainsi de collaborer à la construction de modèles théoriques incorporant cette dimension fondamentale des rapports de genre, à savoir la division sexuelle du travail, à l'analyse critique des limites de la démocratie.

Mots-clés: division sexuelle du travail; démocratie; inégalités; genre

\section{RESUMEN}

\section{División Sexual del Trabajo y Democracia}

El objetivo de este artículo es analizar la relación existente entre la división sexual del trabajo, aquí entendida como un factor fundamental en la producción del género, y los límites de las democracias contemporáneas. El análisis se apoya en la extensa literatura disponible sobre el tema, acompañado de un aporte empírico que permite situar la discusión en el contexto brasileño. Es orientado por dos axiomas y una hipótesis, los cuales corresponden a las tres secciones principales del artículo: (A1) la división sexual del trabajo está en la base de las jerarquías de género en las sociedades contemporáneas; (A2) esas jerarquías asumen formas diferenciadas según la posición de clase y la raza de las mujeres; $(\mathrm{H})$ las asimetrías así constituidas, entre las cuales se destacan el acceso desigual al tiempo libre y a la renta, limitan la participación política de las mujeres. El reconocimiento del impacto de la división sexual del trabajo se hace en una concepción ampliada de la política, que toma en cuenta las relaciones de poder en la cotidianeidad. El análisis resalta la manera en que esas relaciones inciden en el acceso al sistema político. Busca de esta forma colaborar con la construcción de modelos teóricos que incorporen esa dimensión fundamental de las relaciones de género, la división sexual del trabajo, al análisis crítico de los límites de la democracia.

Palabras clave: división sexual del trabajo; democracia; desigualdades; género 